\title{
ENTRELAÇAMENTOS ENTRE ENSINO, PESQUISA E EXTENSÃO EM “OLHARTISTA: PROJETO ARTE NO HOSPITAL"
}

Joana Sanches-Justo

Universidade do Oeste Paulista - UNOESTE, Presidente Prudente, SP. E-mail: joana@unoeste.br

\section{RESUMO}

O presente artigo visa discutir, a partir de uma pesquisa documental, a tríade de ensino, pesquisa e extensão através da práxis de extensionistas do curso de Artes Visuais e de Psicologia da UNOESTE (Presidente Prudente) no projeto de extensão "Olhartista: Projeto Arte no Hospital". Verifica-se a importância da articulação do ensino superior com a pesquisa e com a extensão dos conhecimentos à comunidade e seus desdobramentos na formação do graduando. A coleta e análise dos dados se apoiaram nas diretrizes dos planos e políticas de âmbito nacional e institucional, bem como os documentos gerados pelo projeto de extensão, como os relatórios semestrais. Foi possível observar o compromisso da universidade com a formação discente e com o meio em que está inserida deve articular estes três campos. O conhecimento produzido em âmbito acadêmico deve circular e seguir um curso de transmissão extramuros, para que se torne efetivamente uma práxis.

Palavras-chave: ensino, pesquisa, extensão, práxis, aprendizagem ativa.

\section{ABSTRACT}

The present article aims to discuss, from a documental research, the triad of teaching, research and extension through the praxis of extensionists of the courses of Visual Arts and Psychology of UNOESTE (Presidente Prudente) through the extension project "Artistic Look: Art Project at the Hospital ". This paper aims to contribute to a higher educational articulation with the research and with the extension of the knowledge to the community and its unfolding in the formation of the graduate. The data collection and analysis methodology was based on national and institutional plans and policies, as well as the documents generated by the extension project. It was possible to observe that the University's commitment to the student's education and to its environment its necessary to articulate these three fields. The knowledge produced in the academic field must follow a course of transmission outside the walls, so that it becomes effectively a praxis.

Keywords: teaching, research, extension, praxis, active learning. 


\section{INTRODUÇÃO}

Às vezes ouvimos, na academia, afirmações categóricas sobre o tripé da universidade ser o ensino, a pesquisa e a extensão. Mas, para além de um discurso pronto e naturalizado, como podemos pensar, na prática docente e discente, essa articulação? Qual é a proposta universitária para o exercício deste tripé que fundamenta a formação dos nossos alunos?

Este artigo pretende discutir a importância da amarração desta tríade ensino-pesquisaextensão para a formação do graduando e para a transmissão docente, utilizando como objeto de análise o projeto de extensão "Olhartista: Projeto arte no hospital" desenvolvido no setor de oncologia de um hospital regional no Estado de São Paulo, por uma docente e discentes dos cursos de Psicologia e Artes Visuais da Universidade do Oeste Paulista (UNOESTE).

O projeto acontece semanalmente, desde o primeiro semestre do ano de 2016, no setor de Oncologia em um Hospital do município de Presidente Prudente com o propósito de levar discussões sobre arte para pacientes, acompanhantes e até mesmo funcionários que estão presentes nos ambientes, de forma a instigar discussões, bate-papos e conversas que impulsionem reflexões críticas sobre arte, especialmente arte contemporânea e arte no contemporâneo. A proposta desta extensão é levar os conhecimentos adquiridos e discussões iniciadas em sala de aula à comunidade, no intuito de que tais discussões possam ser fomentadas para além do ambiente acadêmico, firmando um compromisso do estudante não apenas com a arte, mas também com a sociedade.

Assim, a partir da proposta extramuros deste projeto de extensão, iniciou-se uma busca sobre evidenciar a importância deste entrelaçamento entre ensino, pesquisa e extensão à luz do compromisso da Universidade com a formação dos estudantes, mas também com a comunidade na qual está inserida - uma discussão que deve ser sempre reavivada, haja vista a facilidade com que pode se perder de vista o compromisso social no qual deveria se engajar toda e qualquer produção e transmissão de conhecimento.

\section{METODOLOGIA}

Trata-se aqui de uma pesquisa de natureza bibliográfica e documental em que os documentos utilizados foram, além de artigos de revisão de literatura sobre a temática, os Relatórios semestrais dos anos de 2016 e 2017 do Projeto de Extensão Universitária "Olhartista: Projeto Arte no Hospital" cadastrados na PROEXT - Pró-reitoria de Ação e Extensão Comunitária da Universidade do Oeste Paulista - UNOESTE sob o protocolo RF-07386/2017. Outros documentos consultados foram as Diretrizes Curriculares Nacionais do Curso de Graduação em Artes Visuais, o projeto pedagógico do curso de Artes Visuais da UNOESTE e o Plano de Desenvolvimento Institucional da UNOESTE.

Para analisar tais dados, as considerações de Boaventura de Souza Santos e Mary Jane Spink foram de grande importância para trazer questões e embasamentos para o desenrolar de nossas considerações.

\section{RESULTADOS}

De acordo com o Projeto Pedagógico Institucional (PPI) da UNOESTE, o projeto pedagógico dos cursos devem nortear-se pelos seguintes princípios: a autonomia e a gestão democrática (implicando no compromisso e participação de toda comunidade acadêmica), a ética, a criticidade, a criatividade, a flexibilidade e a interdisciplinaridade (que devem fundamentar o eixo norteador na redefinição da organização curricular) e o trabalho coletivo, visando facilitar a produção do conhecimento e de todas as ações pedagógicas.

A teoria aliada à prática implica em assumir uma postura de diversidade e de valorização profissional em relação à produção do conhecimento na organização curricular, na tarefa de formar cidadãos capazes de participar da vida socioeconômica, política e cultural, devendo estar 
voltada para a formação do cidadão, condições de trabalho e remuneração. A valorização profissional que capacita o estudante a participar ativamente da vida socioeconômica, política e cultural é justamente uma formação em que o aluno é incitado a pensar criticamente, a participar ativamente da aquisição de conhecimento, a partir da práxis, ou seja, a conjunção entre a teoria e a prática.

E como essa articulação pode acontecer em uma licenciatura em Artes Visuais? O professor de Artes pode ser também um criador de obras visuais? Pode ser um pesquisador?

No projeto pedagógico do curso de Artes Visuais da UNOESTE os alunos devem desenvolver um trabalho de conclusão de curso que pode ser tomado como o momento derradeiro de articular ensino, pesquisa e extensão. Uma articulação feita pelo aluno, sob tutela de um orientador, que a princípio deve ter em mente, de antemão, tal articulação. Não para oferecê-la ou impô-la ao orientando, mas para abrir-lhe possibilidades de se aprofundar nestas questões e participar ativamente da sua formação acadêmica. O trabalho de conclusão de curso nesta área pode ser desenvolvido tanto como uma pesquisa teórica quanto envolvendo produções artísticas articuladas à análise e crítica de tais produções.

Outro caminho para que se efetive a articulação entre ensino, pesquisa e extensão podem ser as ações extensivas, na medida em que não se voltem apenas a uma prática apartada da produção de conhecimento e do processo de aprendizagem. A extensão não é apenas um fazer, mas sim um saber-fazer estendido à comunidade.

Nesse sentido, o projeto de extensão intitulado "Olhartista: projeto Arte no Hospital" tem como integrantes discentes que desenvolvem pesquisas em projetos de iniciação científica e que desejam transmitir os resultados parciais de suas investigações para além dos muros da academia, em um lugar inusitado para se pensar e discutir arte: o hospital.

Articulando a iniciação científica com a transmissão dos conhecimentos acadêmicos para a comunidade hospitalar, o projeto de extensão "Olhartista: projeto Arte no Hospital" incentiva o pensamento crítico-reflexivo sobre temas relevantes em Artes Visuais e áreas afins; propõe discussões e diálogos com os participantes sobre arte e suas correlações com a vida cotidiana e atualidades contemporâneas, cria condições para que os participantes construam um olhar artístico e estético sobre as obras e temas discutidos e promove a humanização por meio da arte e cultura.

As manifestações artísticas podem produzir transformação e renovação do espaço inóspito do hospital, promovendo a humanização e o bem-estar de pacientes e acompanhantes, tirando-Ihes o foco da dor e da doença, produzindo sensibilizações e reflexões que transformam a percepção sobre o ambiente, sobre si mesmo e sobre o mundo. Dessa forma, no contato com a arte, o participante pode desenvolver seu próprio senso estético e crítico, um novo olhar que pode favorecer a humanização, o resgate da identidade e do repertório cultural despertando novas possibilidades de lidar com o contexto de internação e adoecimento.

O projeto de extensão não visa um olhar terapêutico aos que se encontram internados ou aos que estão ali presentes para receber tratamento quimioterápico diariamente. Ainda assim, ao entrarem em contato com a arte, os pacientes e seus acompanhantes sensibilizam-se, fato que pode promover mudanças significativas no modo de pensar e de perceber o mundo, as situações uma transformação do olhar.

\section{DISCUSSÃO}

Mas como promover a articulação entre estas três instâncias que no ambiente acadêmico podem ser vivenciadas de forma tão dicotomizada? Será mesmo possível ou até mesmo relevante a integração entre o que o conteúdo estudado com a pesquisa e as práticas sociais?

(...) uma revolução científica que ocorre numa sociedade ela própria revolucionada pela ciência, o paradigma a emergir dela não pode ser 
apenas um paradigma científico (o paradigma de um conhecimento prudente), tem de ser também um paradigma social (o paradigma de uma vida decente) (SANTOS, 2008, p. 60).

Santos $(2004 ; 2008)$ insiste que a produção de conhecimento não deve ficar restrita aos muros universitários, mas ser uma extensão da universidade ao cotidiano, um conhecimento prudente para uma vida decente. Vida de quem? Da população, da comunidade. Um conhecimento que fica engessado dentro dos muros acadêmicos não serve ao propósito de emancipação social. O conhecimento tem que circular para além dos muros, no cotidiano.

Nesse mesmo sentido, o projeto pedagógico do curso de Artes Visuais da UNOESTE afirma que "A Pesquisa, vinculada à Pró-Reitoria de Pesquisa e Pós-Graduação, tem por objetivo o desenvolvimento de pesquisas para contribuir com o progresso da ciência e da tecnologia e solução de problemas locorregionais" (UNOESTE, 2015, p.10), ou seja, a produção de conhecimento deve estar em consonância com o contexto social, econômico e político.

Não há, portanto, distinção entre o conhecimento e a ação, uma vez que existe 'intenção de uso' ao se produzir conhecimento (SANTOS, 2008). Essa é a dimensão ética da produção de conhecimento: um compromisso não com a dimensão utilitarista do conhecimento, mas com seu uso social, político, cultural - cotidiano. O conhecimento apartado do cotidiano, da sociedade, perde sua "intenção de uso", afinal, as atividades humanas devem produzir subjetividades autoenriquecedoras na sua relação com o mundo (GUATTARI; ROLNIK, 1989/2005).

A inseparabilidade entre conhecimento e ação é o que articula o ensino, a pesquisa e a extensão, uma vez que se provoca uma mudança paradigmática: em vez de produzir conhecimentos sobre o cotidiano, produz-se no cotidiano.

Se pesquisarmos no cotidiano, seremos partícipes dessas ações que se desenrolam em espaços de convivência mais ou menos públicos. Fazemos parte do fluxo de ações; somos parte dessa comunidade e compartimos de normas e expectativas que nos permitem pressupor uma compreensão compartilhada dessas interações (SPINK, 2007, p. 34).

Participantes da produção de conhecimento e pertencentes à comunidade, os estudantes se tornam o veículo para estender a teoria à prática.

Por sua vez, a Extensão Universitária

tem por objetivo disseminar conhecimentos científicos, tecnológicos e humanísticos e estabelecer linhas de ações e de relações interinstitucionais fundamentadas nas necessidades da sociedade. [...] A extensão universitária, parceria do ensino e da pesquisa no atendimento às necessidades da comunidade, muito contribui para a construção da cidadania, repassando à população conhecimento, tecnologia e cultura de alta qualidade e vanguardismo na área social (PPC-Artes Visuais, p.11-12).

Nos relatórios do projeto de extensão Universitária "Olhartista: Projeto Arte no Hospital" consta que seu escopo é promover o pensamento crítico-reflexivo junto aos pacientes do hospital sobre temas relevantes em Artes Visuais e áreas afins; propor discussões e diálogos com os participantes sobre arte e suas correlações com a vida cotidiana e atualidades contemporâneas.

Quanto à seleção dos discentes participantes do projeto, estes devem estar desenvolvendo uma iniciação científica para ingressar no projeto de extensão, devem elaborar um plano de aula com a temática desenvolvida na pesquisa e posteriormente ministrar uma aula ou dirigir discussões, executando o plano elaborado. Quanto à metodologia das ações extensivas no hospital, no relatório consta que foram ministradas aulas/discussão semanais expositivas e 
dialogadas sobre temas, obras e artistas previamente escolhidos pela coordenadora, juntamente com os alunos e participantes do projeto. Semanalmente os alunos se reuniram com a professora coordenadora do projeto para elaborar o cronograma de atividades, estudar a teoria relacionada ao projeto, discutir as ações extensivas e fazer supervisão das atividades realizadas com os pacientes e acompanhantes.

Além dos planos de aula os alunos produziram diários de campo em que registraram suas vivências e impressões das ações extensivas realizadas nos anos de 2016 e 2017. Tais anotações foram anexadas aos relatórios finais do projeto de extensão e a partir destes documentos é possível perceber que as discussões tem um efeito sobre os pacientes, por exemplo: diminuição da pressão arterial que antes da discussão estava elevada; refletição sobre o corpo enquanto morada da alma; questionamentos a respeito de a adaptação de um vaso sanitário para vaso de flores ser uma obra artística ou um hobby; inspiração para um paciente a produzir obras à moda de Arthur Bispo do Rosário.

Em contrapartida, os relatos evidenciam efeitos também nos discentes - e uma surpresa por parte destes em sentir tais efeitos em si, quando esperavam serem apenas os que afetam e não também afetados pelo contato com os pacientes. Os efeitos relatados foram sensação de cumprir um papel importante, de transmitir conhecimento; desinibição ao se colocar na postura de professor e mediador de discussões; maior compreensão de conteúdos vistos em sala de aula, pela exigência de estudar previamente os temas que foram discutidos no hospital; compreender alguns conceitos e conhecer obras que os pacientes apresentam-lhes, como por exemplo a diferença entre arte e artesanato quando uma paciente comparou o crochê que tinha em mãos com os bordados das obras de Bispo do Rosário.

Estudar, lecionar, promover discussões, compreender e se surpreender foram algumas experiências resultantes da participação neste projeto de extensão. Sob esta óptica, a extensão não se resume a um fazer, tanto quanto a pesquisa não envolve apenas o teorizar e o ensino não se restringe à academia.

\section{CONCLUSÃO}

Existe uma tendência dicotomizante em se tomar a pesquisa como uma atividade exclusivamente teórica e a extensão como exclusivamente prática. Este viés equivocado traz como consequência a fragmentação da aprendizagem, situação em que o estudante encontra sérias dificuldades em estabelecer correlações entre disciplinas teóricas e práticas, iniciação científica, estágios e ações extensivas. Ora, é impossível realizar uma ação extensiva junto à comunidade sem ter planejado e estudado a ação. É uma questão de ética de trabalho e responsabilidade.

Da mesma forma, a pesquisa é tomada como uma atividade restrita a um conhecimento adquirido em livros e periódicos, como se o conhecimento produzido não circulasse para além dos muros acadêmicos. De fato, o conhecimento produzido na Universidade pode nunca chegar à população. O caminho para que isso aconteça é justamente uma boa articulação entre o que se apreende em sala de aula, o que se pesquisa a partir disso e o que podemos oferecer à comunidade como fruto destas produções de conhecimento.

As atividades de pesquisa e extensão, articuladas com o ensino permitem que o aluno perceba que "criar e conhecer são indissociáveis e a flexibilidade é condição fundamental para aprender;" (PPC-Artes Visuais, p.35). Ou seja, o estudante deve ser ativo nesse processo de aquisição, produção e promoção do conhecimento produzido na Universidade, como salienta Spink (2007), deve ser partícipe. Assim, a articulação do tripé universitário é importante para que haja a transposição de uma barreira que separa o conhecimento e o cotidiano, a universidade e a comunidade. Articular conhecimento e sociedade é promover a práxis.

Nesse sentido, o projeto de extensão Universitária "Olhartista: Projeto Arte no Hospital", ao requisitar para o ingresso nas ações extensivas que o estudante esteja desenvolvendo uma 
iniciação científica e que um plano de aula seja elaborado a partir destes estudos, abre caminho para que o próprio estudante teça articulações entre o que aprende em sala de aula, o conhecimento que elabora no desenvolvimento de sua pesquisa científica e a transmissão destes conteúdos para a comunidade, no hospital regional. Um entrelaçamento que, para a surpresa dos estudantes, não apenas tem efeito nos pacientes que participam das discussões, mas também em si mesmos. Puderam experimentar uma nova forma de transmissão de conhecimento, que não é unilateral, que não é apenas dar, mas também estar nela implicados de forma que são transformados por essa experiência.

\section{REFERÊNCIAS}

GUATTARI, F.; ROLNIK, S. Micropolítica: Cartografias do desejo. 7. Ed. rev. Petrópolis: Vozes, 2005.

SANTOS, B. S. Um discurso sobre as ciências. São Paulo: Cortez, 2008.

SANTOS, B. S. (Org.) Conhecimento prudente para uma vida decente: um discurso sobre as ciências revisitado. São Paulo: Cortez, 2004.

SPINK, M. J. P. Pesquisando no cotidiano: recuperando memórias de pesquisa em psicologia social. Psicologia \& Sociedade,[s.I.], v. 19, n.1, p.7-14, jan/abr 2007.

UNIVERSIDADE DO OESTE DO PAULISTA. Projeto Pedagógico do Curso de Artes Visuais. Presidente Prudente: UNOESTE, 2015. 213 p.

UNIVERSIDADE DO OESTE DO PAULISTA. Projeto Pedagógico Institucional. 2013-2017. Presidente Prudente: UNOESTE, 2013. $81 \mathrm{p}$. 